\title{
The Protective Role of Moringa oleifera Against Effects of Electromagnetic Field on Blood of Albino Rats
}

\author{
Shoman, H.M*; Aida A. Salama **; Aziza A. Elsaeid **1 and Ola Mohamed \\ Awad ** \\ *Zoology Department, Faculty of Science, Al-Azhar University, Cairo, Egypt. \\ ** Biophysics Department, Faculty of Science, Al-Azhar University, Cairo, Egypt.
}

$\mathbf{T}$

HE aim of this study is to reveal the protecting role of Moringa oleifera leaf extract against the exposure to electromagnetic field (EMF) effects on rat blood. Forty two adult white Albino male rats, weighting (150-180 g) were divided into six equal groups. The first group is the control while the second group was orally supplemented daily with $(200 \mathrm{mg} /$ $\mathrm{kg}$ ) of Moringa oleifera leaves extract (MOLE) for six days. The third group was continuous exposed to EMF of $1.5 \mathrm{mT}, 50 \mathrm{~Hz}$ for 9 hours. The other three groups were exposed to the same EMF and Moringa extract in different ways (before, after and before and after the exposure of magnetic field). Blood samples were collected and hemoglobin extracted. The relative viscosity and conductivity were measured. Blood films were also taken for histological examination. The results showed significant increase in relative viscosity and conductivity of hemoglobin molecules. Microscopic examination of blood films showed alterations in different shapes and pale in color of red blood cells with aggregation to form rouleaux. Lymphocytes degeneration was also observed. The results of groups which treated with Moringa showed good repairing in all results. So this study concludes that impairments caused by EMF on blood can be decreased by Moringa oleifera leaf extract.

\section{Introduction}

All electric instruments can produce in their vicinity an electromagnetic field which is propagated in space in the form of non-ionizing electromagnetic radiations (Touitou et al., 2013). The blood is a pathophysiological indicator of the whole body so blood parameters are important in analyzing the physical and physiological status of the living organisms exposed to toxicity (Adhikari et al., 2004). Moderate intensity static magnetic fields caused alterations of cell surface, cell shape and cytoskeleton (Dini and Abbro, 2005). El- Dahshan (2006) investigated the effect of exposure to 50 $\mathrm{Hz}$ and $2 \mathrm{mT}$ alternating magnetic field (AMF) on male mice. Many pathological changes in the red blood cells, liver, kidney, spleen and testis were found. Erythrocytes showed distortion, contraction and irregular pear shape. Also, Cakir et al., (2009) evaluated the effects of extremely low frequency electromagnetic waves on blood parameters of rats. They found significant decrease in Eosinophil, hemoglobin and mean platelet volume levels in rats which were exposed to EMF for 50 days. On another study it was showed that electrical conductivity of hemoglobin of the animals which exposed to static magnetic fields as compared to control group showed significant increase for group exposed to 0.5 Tesla and a very high significant increase for groups exposed to 1.0 and 1.5 Tesla (Hassan and Abdelkawi, 2010). Moringa oleifera is most cultivated in tropical and subtropical countries. The leaves of these plants are highly value nutritious, they rich with vitamins $\mathrm{A}, \mathrm{B}, \mathrm{C}$ and $\mathrm{E}, \beta$-carotene, nicotinic acid, folic acid, protein, various phenolic compounds, amino acids and minerals Khalafalla et al., (2010). Moringa oleifera can regulate thyroid status and have radio-protective influence. This plant has also been reported to be hepatoprotective against anti-tubercular drug and acetaminophen Fakurazi et al., (2008) and Mansour et al., (2014). Therefore, the purpose of this study is to evaluate the protective effect of Moringa oleifera leave extract against damage induced by electromagnetic radiation in blood of rats. Ari-egoro et al. (2019) studied the effects of Moringa oleifera on some haematological parameters of rats. They concluded from their results on Red blood cell, Packed Cell Volume, haemoglobin and lymphocyte of the animals that Moringa oleifera possesses nutritional benefits. 


\section{Materials and Methods}

Experimental animals

In this study 42 white Albino male rats, weighing 150-180 g were involved. The animals were divided into six equal groups; 7 rats in each one.

Group (A): the control group received only .1-standard diet

2- Group (M): was supplemented orally daily with $200 \mathrm{mg} / \mathrm{kg}$ of Moringa oleifera leaves extract (MOLE) for six days.

3- Group (B): was exposed to EMF $1.5 \mathrm{mT}, 50 \mathrm{~Hz}$ for 9 hours..

4- Group (T): was exposed to EMF $1.5 \mathrm{mT}, 50 \mathrm{~Hz}$ 9 hours then supplemented daily and for six days with $200 \mathrm{mg} / \mathrm{kg}$ of MOLE.

5- Group (N): was supplemented daily with 200 $\mathrm{mg} / \mathrm{kg}$ of Moringa oleifera leaves extract (MOLE) for six days then exposed to EMF of $1.5 \mathrm{mT}, 50 \mathrm{~Hz}$ for 9 hours

6- Group (C): supplemented orally daily with $200 \mathrm{mg} / \mathrm{kg}$ of MOLE for three days then exposed to EMF of $1.5 \mathrm{mT}, 50 \mathrm{~Hz} 9$ hours then supplemented daily with $200 \mathrm{mg} / \mathrm{kg}$ MOLE for three days.

\section{Electromagnetic field exposure device}

The device of exposure consists of a coil placed on a wooden rack which has 320 turns of $2 \mathrm{~mm}$ copper wire wounded around a cupper cylinder of $2 \mathrm{~mm}$ thick, $50 \mathrm{~cm}$ in diameter and 60 $\mathrm{cm}$ in length. The ends of the coil were connected to a variac that was fed from the mains (220 Vpp and $50 \mathrm{~Hz}$ ) through stabilizer to produce the alternating magnetic fields. The magnetic field strength inside the magnetic chamber was adjusted by changing the voltage across the coil by the variac to produce magnetic field of $1.5 \mathrm{mT}$ in the area where the animals housed as showed in Fig 1.

\section{Ethanolic Moringa oleifera leaves extract}

Moringa oleifera leaves ethanolic extract was prepared according to the technique mentioned in the work of Okechukwu et al., (2013). Frist leaves were dried at $29-35^{\circ} \mathrm{C}$ for three weeks then leaves were grinded. The grinded leaves were extracted (using soxhlet extractor unit) by absolute ethanol and left for 48 hours. Then the extract was evaporated to dry using rotary evaporator at $40-45^{\circ} \mathrm{C}$. The extract was diluted using a polysaccharide to $1000 \mathrm{ml}$ as a carrier and kept in the fridge. Then, this extract was diluted by distilled water to equilibrate $1 \mathrm{~kg}$ of leaves powder/Liter.

\section{Collection of blood samples:}

The rats were anaesthetized with diethyl ether. Blood samples were taken from the animals by draining the blood from eyes into heparinized tube, using capillary tubes. The tubes sealed and gently checked ready for performing measurements. Hemoglobin was extracted by a modification of the method of Trivelli et al., (1971).

Relative viscosity and Conductivity measurementsBefore Viscosity and conductivity measurements, hemoglobin concentration was adjusted by an appropriate dilution with deionized water at room temperature $\left(25 \pm 1^{\circ} \mathrm{C}\right)$ on the base of heme absorption band at $576 \mathrm{~nm}$ where the absorbance of $\mathrm{Hb}$ at $576 \mathrm{~nm}=0.5$.

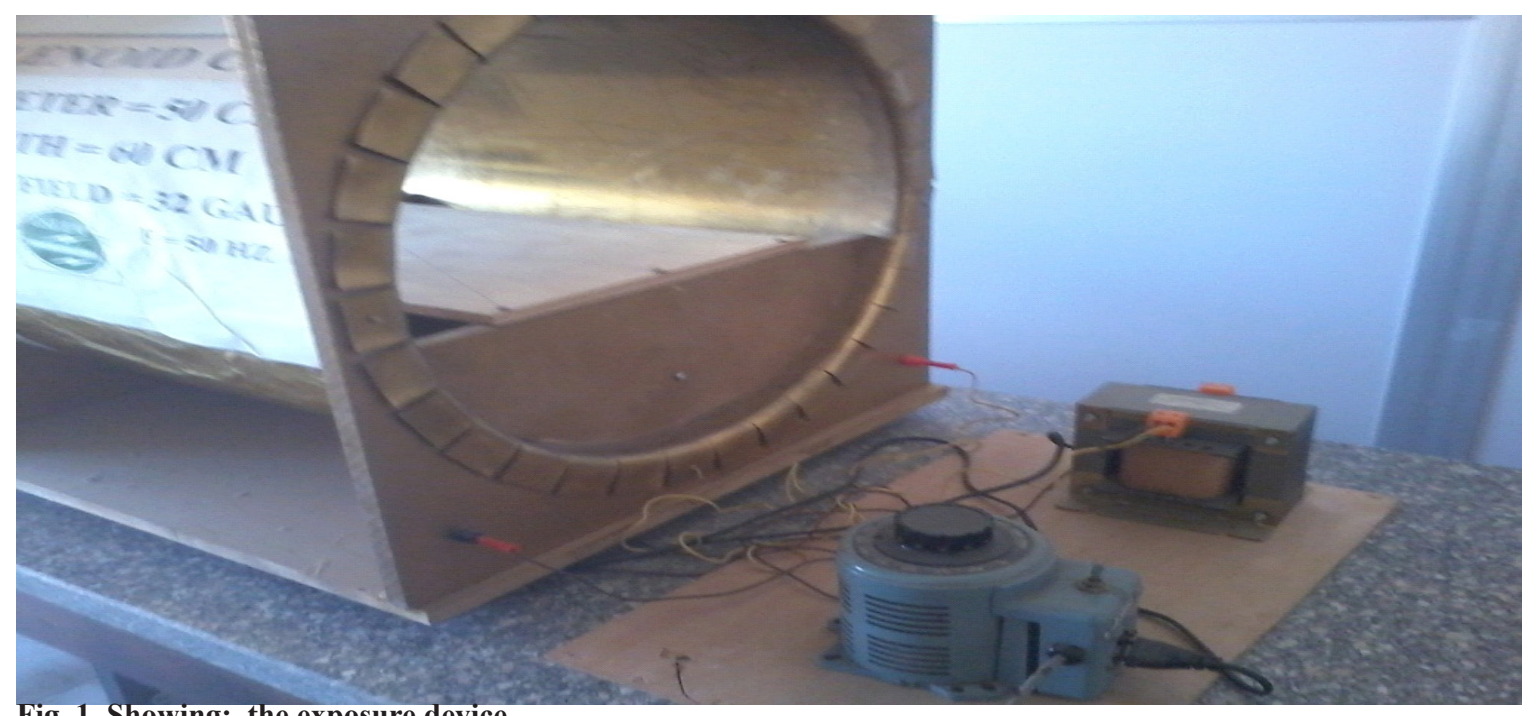

Fig. 1. Showing: the exposure device.

Egypt. J. Biophys. Biomed. Eng., Vol.21 (2020) 
The relative viscosity was calculated at constant temperature by measuring the time of flow of constant volume of samples and water by using Ostwald viscometer from equation: $\eta_{\mathrm{s}} / \eta_{\mathrm{w}}$ $=\mathrm{d}_{\mathrm{s}} \mathrm{t}_{\mathrm{s}} / \mathrm{d}_{\mathrm{w}} \mathrm{t}_{\mathrm{w}}$

Where $\eta, d$, and $t$ are viscosity, density and time of flow respectively for the sample (s) and water (w). The electrical conductivity was determined by a conductivity meter type HI 8633 , with a dip type cell which has fully protected electrodes made by Hanna instruments manufactured in Germany.

\section{Blood Films}

Blood films were prepared by distribution a drop of blood on a microscope slides by another slide which make $45^{\circ}$ with it, and then fixed by $95 \%$ alcohol and stained by hematoxylin and eosin- Y alcoholic solutions for microscopic examination of blood cells (Bancroft and Gamble, 2002).

\section{Statistical Analysis}

Data were statistically analyzed by ANOVA test (SPSS version17).

\section{$\underline{\text { Results }}$}

Viscosity and electrical conductivitymeasurements

This study investigated that EMF induced high significant increase in viscosity and electrical conductivity of hemoglobin $(\mathrm{P}<0.001)$ as shown in Figs. $(2,3)$ respectively. Animals which treated with MOLE showed improvement in all treatments design. The most improvement was found in group $(\mathrm{N})$.

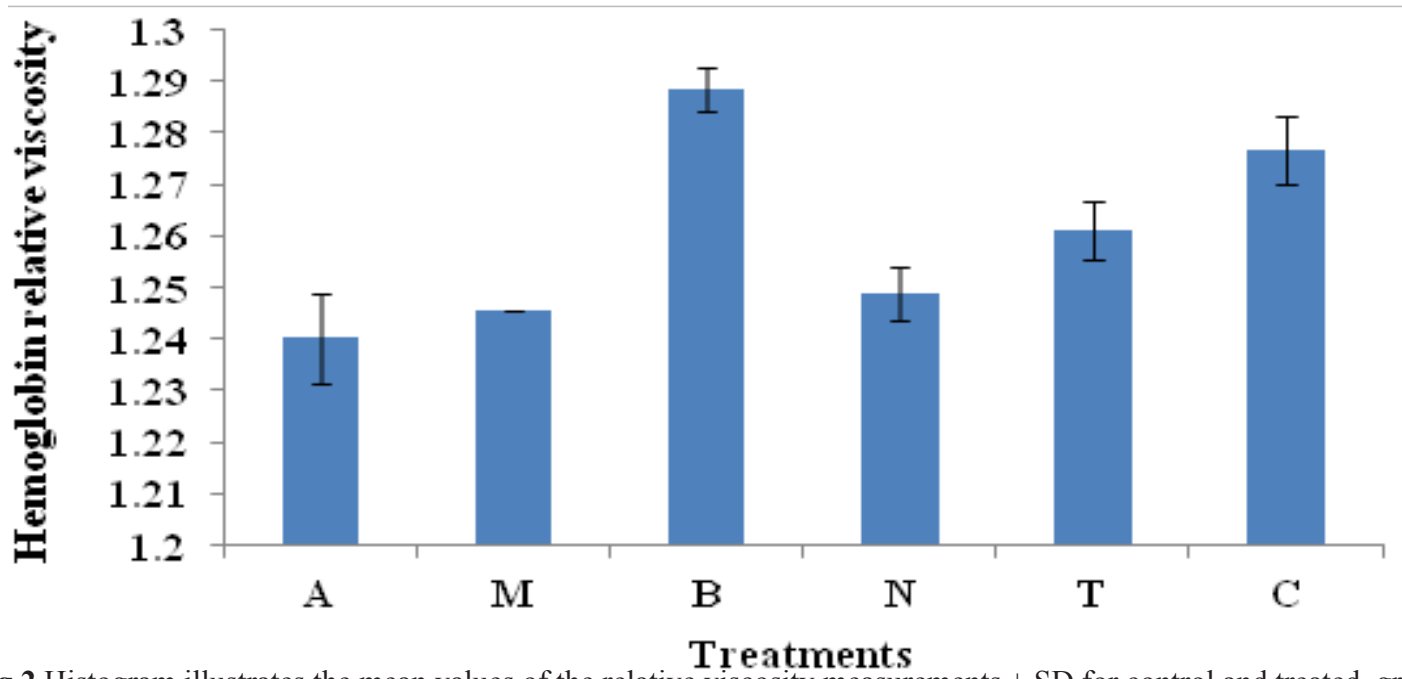

Fig.2.Histogram illustrates the mean values of the relative viscosity measurements \pm SD for control and treated groups.

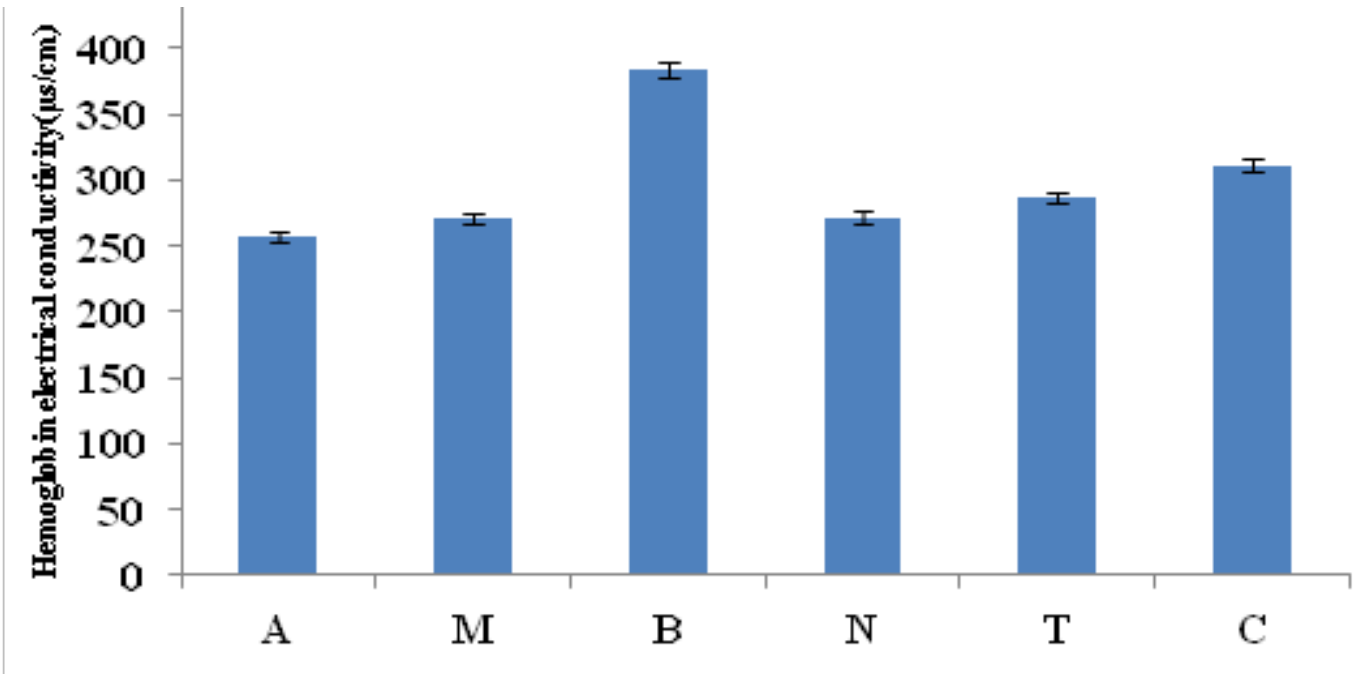

Fig.3. Histogram illustrates the mean values of the electrical conductivity measurements in $(\mu \mathrm{s} / \mathrm{cm}) \pm \mathrm{SD}$ for control and treated groups. 


\section{Blood films}

Blood films of control and treated mice groups were showed in Figs. (4-9). Blood films of control rats group (A) and group (M) (Figs.4\&5) respectively showed the normal characteristic features of the blood.The red blood corpuscles (r) stained pink due to their high content of hemoglobin, While the pale staining of its central region is a result of the biconcave shape. Normal appearance of different leukocytes (L) was also detected. On the other hand, histopathological changes were found in blood films of exposed group (B), the red blood corpuscles having different shapes, disorga-
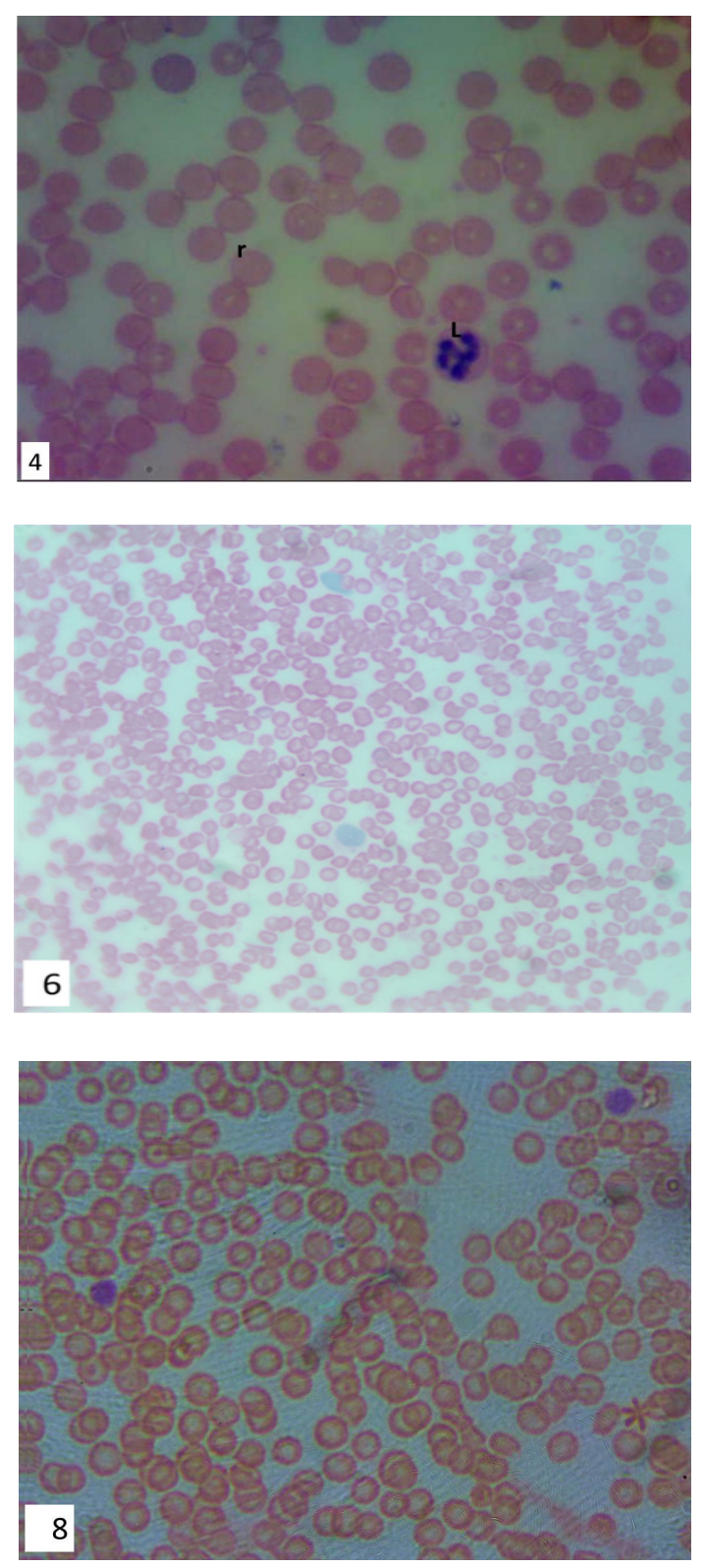

Figs.4-9. Shows the Photomicrographs of blood films for (A)control group (fig.4),group M(fig.5),group B (6) and treated groups $\mathrm{N}, \mathrm{T}$ and $\mathrm{C}$ (figs.7-9)respectively (H\&E X 400).

Egypt. J. Biophys. Biomed. Eng., Vol.21 (2020)

nized and unequal size (anisocytosis). Some of the erythrocytes have irregular outline cell membrane, hemolysis of the blood cells and faint staining of the blood tissue was noticed. Also there is an aggregation of blood cells with each other. Sings of lymphocytes degeneration were also observed (Fig.6). The microscopic examination blood films of rats treated with Moringa oleifera leaves extract MOLE in all treatments showed noticeable improvement when compared with group (B). However, some histopathological changes still found such as aggregation of some red blood cells and degeneration of some leukocytes (Figs.7-9).
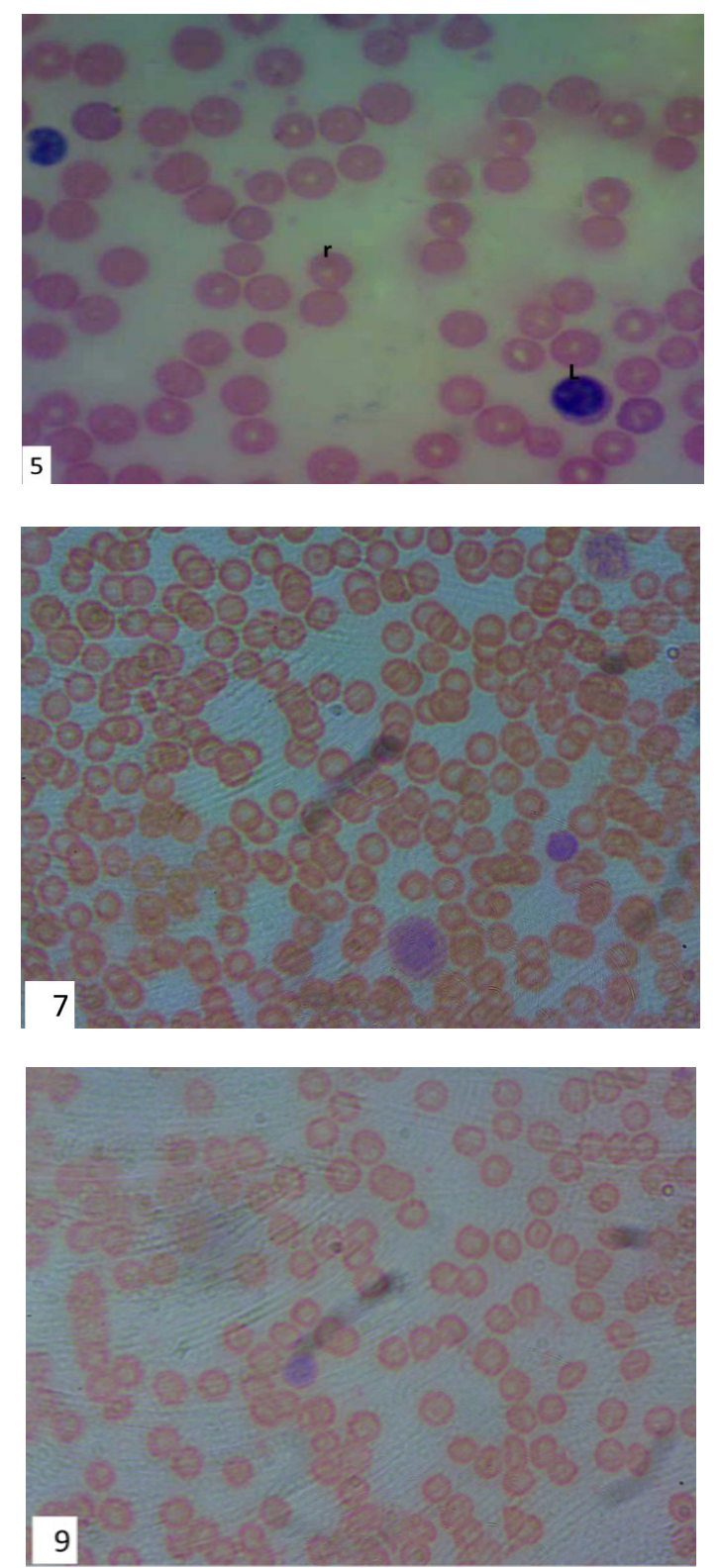


\section{Discussion}

Measurements of blood physical and biological parameters are most important indicator for knowing health status of living organisms (Soud, 2004). The elevation in the relative viscosity of hemoglobin in the exposed rats may be due to the magnetic field caused an aggregation and unfolding of $\mathrm{Hb}$ molecules due to the effect on protein parts. This in turn leading to increase in the viscosity of hemoglobin, this finding in agreement with Szweda-Lewandouska and Leyko, (1987) who investigated that the changes in the dimensions and shape of hemoglobin molecules under the influence of magnetic field shows a change in viscosity. Also, Vanhuld, (1971) reported that, the functional loss of kidney causing an increase in creatinine level. This toxic substance may give a denatured effect on the globular protein molecules, that accompanied by increase in their volume in solution. This increase indicate the change in the dimensions and shapes of $\mathrm{Hb}$, which leads to increase in viscosity of $\mathrm{Hb}$. The increment in conductivity of hemoglobin in exposed animals may be due to that EMF caused unfolding of globular protein. This finding in agreement with Hassan and Abdelkawi, (2010) who found that exposure to magnetic field in the range of 0.5-1.5 $\mathrm{T}$ causing increasing in electrical conductivity due to unfolding of globular protein. increased ability to stick together due to increased viscosity of blood consequence of exposure to electromagnetic field. . Most of the red blood cells appear pale in color because of lack of concentration of hemoglobin Singh et al., (2013). The results were supported by El- Dahshan, (2006) who found that of exposure of male mice to $50 \mathrm{~Hz}$ and $2 \mathrm{mT}$ alternating magnetic field (AMF) cause alteration in blood film including erythrocytes distortion, contraction and irregular pear shape. Also, El Saeid and Mohamed,(2016) reported that the blood samples from rats groups exposed to $0.5 \mathrm{mT}$ and $1.5 \mathrm{mT}$ magnetic field (MF) show that, red blood cells serrated with the edge, the cells called Echinocytes erythrocytes. In addition, RBCs were staked next to each other to form rouleaux as well as pale corpuscles can be noted. In the present study, MOE was used as anti-electromagnetic radiation induced effects and this is due to that Moringa oleifera micronutrients contain antitumor, anti-epileptic, anti-diuretic, anti-inflammatory and venomous bite characters. Moringa oleifera extract (MOE) contains specific plant pigments with demonstrated powerful anti-oxidative ability such as vitamins C, E, A, caffeoylquinic acids, carotenoids-lutein, alphacarotene and beta carotene, kaempferol, quercetin, rutin Akunna et al., (2012) and Maida et al. (2005). This finding in agreement with Bin-Meferij and El-kott, (2015) who reported that chronic exposure to electromagnetic radiation resulted in testicular injury which can be decreased by Moringa oleifera leaf extract.

\section{Conclusion}

This study indicates that the exposure to EMF may cause changes on physical properties of hemoglobin such as viscosity and conductivity and red blood cells morphological structure. These changes were improved by Moringa oleifera leaf extract. So, it can be concluded that Moringa oleifera leaf extract had a protective role against the damage caused by exposure to electromagnetic field.

\section{$\underline{\text { References }}$}

Adhikari, S.; Sarkar, B.; Chatterjee, A.; Mahapatra, C.T. and Ayyappan, S. (2004): Effects of Cypermethrin and Carbofuran on Certain Hematological Parameters and Prediction of their Recovery in aFreshwater Teleost, Labeo rohita (Hamilton). Ecotoxicol and Environ Safety. 58: 220-226.

Akunna, G.G.; Ogunmodede, O.S.; Saalu, C.L.;Ogunlade, B.;Bello, A.J. and Salawu EO. ( 2012): Ameliorative effect of Moringa oleifera (drumstick) leaf extracts on chromium-induced testiculatoxicity in rat testes. World J Life Sci Med Res, 2: 20 .

Ari-egoro, Y.E.; Ayodele, P.F. and Oyeleke, O.M.(2019): Effects of graded levels of Moringa oleifera leaf-Meal in albino rat diet on some hematological parameters. JAnal Tech Res 1 (2): 037-046.

Bancroft, J. D. and Gamble, M. (2002): Theory and Practice of Histological Techniques.5th (Ed.) Churchill Livingstone, Londone, 153.

Bin-Meferij, M.M. and El-kott, A.F. (2015): The radioprotective effects of Moringa oleifera against mobile phone electromagnetic radiation-induced infertility in rats. Int J Clin Exp Med; 8: 12487-12497.

Cakir, D.U.; Yokus, B.; Akdag, M. Z.; Sert, C. and Mete, N. (2009): Alterations of hematological variations in rats exposed to extremely low frequency magnetic fields $(50 \mathrm{~Hz})$. Archives of Medical Research, (40):352- 356.

Egypt. J. Biophys. Biomed. Eng., Vol.21 (2020) 
Dini, L. and Abbro, L. (2005): Bio effects of moderate intensity static magnetic fields on cell cultures. Micron. 36 (3): 195-217.

EI Saeid, A. and Mohamed, M. (2016): Effects of Whole Body Exposure Extremely Low Frequency Magnetic Field (ELFMF) on Physical and Biological Parameters in vivo Rats. International Journal of Environment 5 (1): 1-8.

El-Dahshan, A.A. (2006): Study the effect of magnetic field on RBCs and certain organs of mice. M.Sc. Thesis, Zoology Department, Faculty of Science, Al-Azhar University, Cairo.

Fakurazi, S.; Hairuszah, I. and Nanthini, U.(2008): Moringa oleifera Lam prevents acetaminophen induced liver injury through restoration of glutathione level. Food Chem Toxicol 46: 2611-5.

Hassan, N. S. and Abdelkawi, S.A. (2010): changes in molecular structure of hemoglobin in exposure to $50 \mathrm{~Hz}$ magnetic fields. Nature and Science. 8 (8): 236-243.

Khalafalla, M. M.; Abdellatef, E.; Dafalla, H. M.; Nassrallah, A. A.; Aboul-Enein, K. M.; Lightfoot, D. A.; El-Deeb, F. E.and El-Shemy, H. A. (2010): Active principle from Moringa oleifera Lam leaves effective against two leukemias a hepatocarcinoma. African Journal of Biotechnology, 9 (49): 84678471.

Maida, A.; Farooq, A.; Raziya, N.; Umer, R.; Kazi, T. and Nadeem, M. (2005): Mineral Composition of Moringa oleifera leaves and pods from different regions of Punjab, Pakistan. Asian Journal of Plant Sciences.

Mansour, H.H.; El Azeem, M.G.A. and Ismael, N.E. (2014): Protective Effect of Moringa oleifera on $\gamma$-Radiation-Induced Hepatotoxicity and Nephrotoxicity in Rats. American Journal of Phytomedicine and Clinical Therapeutics, 2:495508.

Okechukwu, P.U.; Okwesili, F.N. and Parker, E.J., (2013): Phytochemical and acute toxicity studies of Moringa oleifera ethanol leaf extract. Int J Life Sci Btand Pharm. 2(2):66-71.

Singh, H.; Kumar, C. and Bagai, U. (2013): Effect of electromagnetic field on red blood cells of adult male swiss albino mice. International Journal of Theoretical \& Applied Sciences 5(1): 175-182.

Soud, R. (2004): Human and the Environment (Education Study of the Environment) Dar AlHamed for Publication and Distribution," Journal

Egypt. J. Biophys. Biomed. Eng., Vol.21 (2020) of Environmental Studies, 1, 23-31.

Szweda-Lewandouska, Z. and Leyko, W. (1987): Effect of guanidine and hydrochloride and buffers of various $\mathrm{pH}$ on human hemoglobin. Stud. Biophys. 120:23.

Touitou, Y.; Djeridane, Y.; Lambrozo, J.; Camus, F. and Selmaoui, B. (2013): Long-term (up to 20 years) effects of 50-Hz magnetic field exposure on immune system and hematological parameters in healthy men. Clinical Biochemistry (46): 59-63.

Trivelli, L.A.; Ranney, H. M. and Lai, H. T. (1971): Hemoglobin components in patients with diabetes mellitus. N. Eng. J. Med. 353-362.

Vanhuld, K.E. (1971): "Viscosity in physical Biochemistry" prentice-Hall, INC. Englewood Chiffs, New Jersy, 141.

Received 31/3/2020; accepted 24/6/2020 


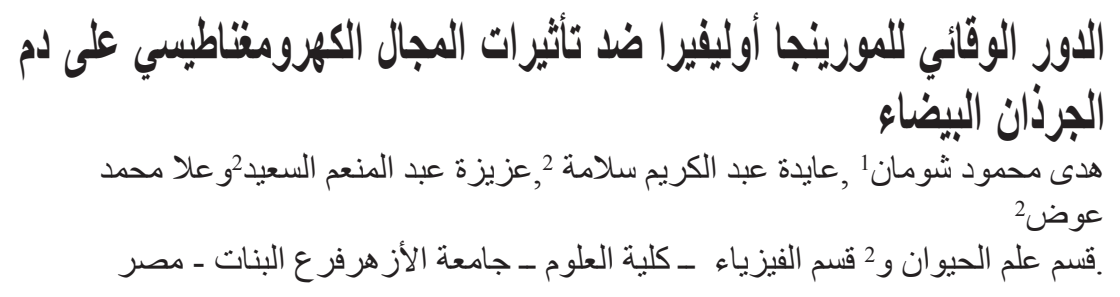

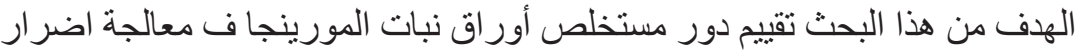

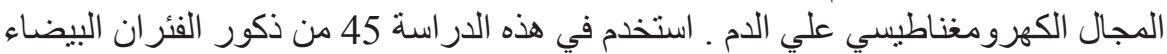

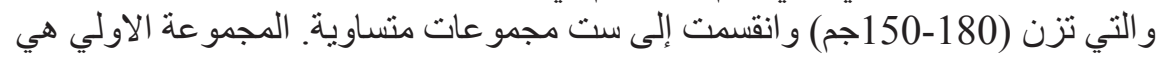

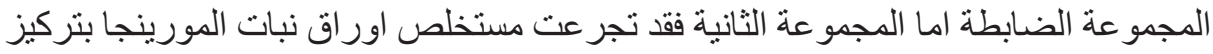

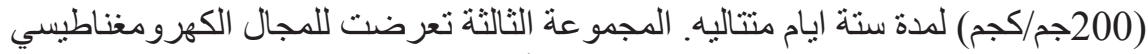

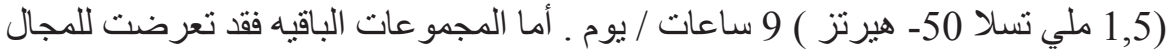

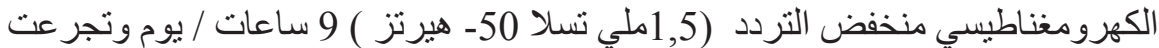

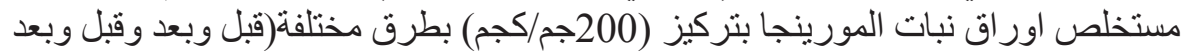

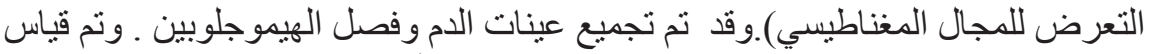

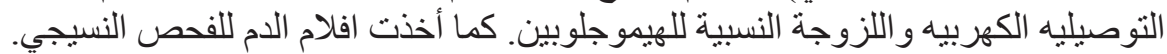

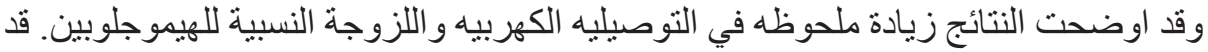

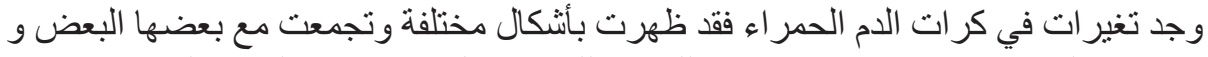

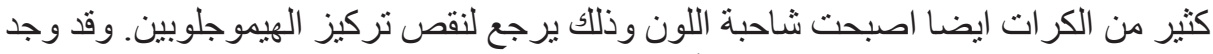

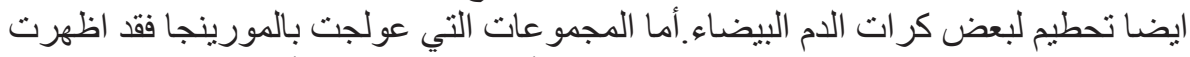

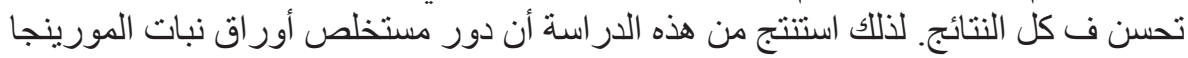

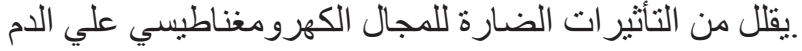

